\title{
Neurocognitive and Psychotiform Behavioral Alterations and Enhanced Hippocampal Long-Term Potentiation in Transgenic Mice Displaying Neuropathological Features of Human $\alpha$-Mannosidosis
}

\author{
Rudi D'Hooge, ${ }^{1}$ Renate Lüllmann-Rauch, ${ }^{3}$ Tom Beckers, ${ }^{2}$ Detlef Balschun, ${ }^{5}$ Michael Schwake, ${ }^{4}$ Karina Reiss, ${ }^{4}$ \\ Kurt von Figura, ${ }^{6}$ and Paul Saftig ${ }^{4}$ \\ ${ }^{1}$ Laboratory of Biological Psychology and ${ }^{2}$ Centre for Learning Psychology and Experimental Psychopathology, University of Leuven, B-3000 Leuven, \\ Belgium, ${ }^{3}$ Anatomical Institute and ${ }^{4}$ Biochemical Institute, University of Kiel, D-24098 Kiel, Germany, ${ }^{5}$ Leibniz Institute for Neurobiology, D-39118 \\ Magdeburg, Germany, and 'Biochemistry and Molecular Cell Biology, University of Göttingen, D-37073 Göttingen, Germany
}

\begin{abstract}
Mice with $\alpha$-mannosidase gene inactivation provide an experimental model for $\alpha$-mannosidosis, a lysosomal storage disease with severe neuropsychological and psychopathological complications. Neurohistological alterations in these mice were similar to those in patients and included vacuolations and axonal spheroids in the CNS and peripheral nervous system. Vacuolation was most prominent and evenly distributed in neuronal perikarya of the hippocampal CA2 and CA3 regions, whereas CA1 and dentate gyrus were weakly or not affected. Field potential recordings from CA1 region in hippocampal slices showed enhanced theta burst-induced long-term potentiation (LTP) in $\alpha$-mannosidase-deficient mice. Longitudinal assessment in age-matched $\alpha$-mannosidase-deficient and wild-type littermates, using an extended test battery, demonstrated a neurocognitive and psychotiform profile that may relate to the psychopathological alterations in clinical $\alpha$-mannosidosis. Brainstem auditory-evoked potentials and basic neuromotor abilities were not impaired and did not deteriorate with age. Exploratory and conflict tests revealed consistent decreases in exploratory activity and emotional blunting in the knock-out group. $\alpha$-Mannosidosis mice were also impaired in aversively motivated learning and acquisition of signal-shock associations. Acquisition and reversal learning in the water maze task, passive avoidance learning in the step-through procedure, as well as emotional response conditioning in an operant procedure were all impaired. Acquisition or shaping of an appetitive instrumental conditioning task was unchanged. Appetitive odor discrimination learning was only marginally impaired during shaping, whereas both the discrimination and reversal subtasks were normal. We propose that prominent storage and enhanced LTP in hippocampus have contributed to these specific behavioral alterations in $\alpha$-mannosidase-deficient mice.
\end{abstract}

Key words: behavior; degeneration; metabolism; neuropathology; storage; learning and memory; knock-out mice

\section{Introduction}

$\alpha$-Mannosidosis is caused by deficiency of lysosomal $\alpha$-mannosidase (EC 3.2.1.24), an exoglycosidase that cleaves $\alpha$-linked mannose residues during glycoprotein catabolism (Aronson and Kuranda, 1989). Ensuing lysosomal storage of undegraded oligosaccharides affects various physiological functions, but CNS impairments are prominent (Bennet et al., 1995). Effective and safe treatment is not yet available, and it cannot be

Received Jan. 20, 2005; revised May 3, 2005; accepted May 31, 2005.

This work was supported by the Katholieke Universiteit Leuven KUL2004 Impulse Program to the Laboratory of Biological Psychology. T.B. is a postdoctoral fellow of the Fund for Scientific Research-Flanders. This work was also supported by Fonds der Chemischen Industrie and European Commission Contract QLK3-CT2001-02458 (P.S., K.v.F.) We thank Leen Van Aerschot, Jo Tambuyzer, and Dagmar Niemeier for excellent technical assistance. This publication does not necessarily represent the opinion of the European Community, and the European Community is not responsible for any use that might be made of data appearing in this publication.

Correspondence should be addressed to Rudi D'Hooge, Laboratory of Biological Psychology, Tiensestraat 102, Katholieke Universiteit Leuven, B-3000 Leuven, Belgium. E-mail: rudi.dhooge@psy.kuleuven.be.

DOI:10.1523/JNEUROSCI.0283-05.2005

Copyright $\odot 2005$ Society for Neuroscience $\quad$ 0270-6474/05/256539-11\$15.00/0 successfully prevented in diagnosed children. Bone marrow transplantation could help in some cases, but enzyme replacement, gene therapy, or combination therapies seem to be the most promising options (Sun and Wolfe, 2001; Roces et al., 2004).

A continuum of phenotypes has been described ranging from severe infantile (type I) through milder (type II) forms with survival into adulthood (Thomas, 2001). Many patients develop neuromotor disabilities and ataxia (Autio et al., 1982), as well as hearing impairments that affect receptive language abilities (Noll et al., 1989). Neurocognitive defects have been described in all children with $\alpha$-mannosidosis, but severity, age of onset, and progression are variable and unpredictable (Autio et al., 1982). Visuomotor integration and other neurocognitive domains are affected (Noll et al., 1989; Grewal et al., 2004) and may further deteriorate with age (Shapiro et al., 1995; Grewal et al., 2004). However, scores for general intelligence and visuospatial abilities remained remarkably stable in a 6-year follow-up of three 
$\alpha$-mannosidase-deficient brothers (Noll et al., 1986, 1989). In two patients with type II phenotype, their severe neuropsychological deficiency did not progress over a period of 25 years (Ara et al., 1999). Psychopathological alterations include hyperphagia (Owayed and Clarke, 1997) and recurrent paranoidhallucinatory episodes (Seidl et al., 2005). Psychosis was also described in one of three siblings with rare adult $\alpha$-mannosidosis (Gutschalk et al., 2004).

$\alpha$-Mannosidosis has been described in cattle (Hocking et al., 1972), cat (Burditt et al., 1980), and guinea pig (Muntz et al., 1999; Berg and Hopwood, 2002), but mice are considered more practical laboratory animals (Suzuki et al., 1999). Mice with lysosomal $\alpha$-mannosidase gene inactivation reproduce the pathognomonic histopathology and oligosaccharide storage of human $\alpha$-mannosidosis, but their behavior was not examined (Stinchi et al., 1999). Recently, Roces et al. (2004) reported marked correction of storage in various tissues, notably also including brain, after enzyme replacement in this model.

In view of their further use in pathophysiological and therapeutic experiments, we performed a longitudinal behavioral assessment in a cohort of $\alpha$-mannosidase-deficient female mice and their wild-type littermates. In relation to the observed behavioral defects, we investigated storage-related neuropathological changes that were not previously shown in these animals and long-term potentiation (LTP) of field potentials in hippocampal slices. The extent and complexity of the neurocognitive and psychopathological alterations in human $\alpha$-mannosidosis patients necessitated the use of a test battery that covered various behavioral domains. The battery used in the present study included test for locomotor activity, neuromotor and auditory abilities, open field and social exploration, anxiety, and various cognitive tasks. Specifically, we examined passive avoidance learning, visuospatial learning, odor discrimination learning, and emotional response learning in these animals.

\section{Materials and Methods}

Animals and sample size. Mice with targeted disruption of the $\alpha$-mannosidase gene were generated from $129 / \mathrm{SvEv}$ embryonic stem cells as described previously (Stinchi et al., 1999). The presently used mice were females typically backcrossed onto a C57BL/6J background (for three generations) and had black furs and eyes. Homozygous $(-/-$ ) $\alpha$-mannosidase-deficient animals showed a complete absence of all lysosomal $\alpha$-mannosidase activity.

The present cohort of $17 \alpha$-mannosidase knock-out mice and 14 wildtype littermates was bred in the University of Göttingen animal facilities and transferred to the University of Leuven at the age of 2 months. Sample size resulted from recommendations in the literature (Crawley, 1999) and by the ethical research committee, the number of age-matched females available at the time of the study, and a priori effect size estimates in water maze experiments. Only female mice were used to avoid territorial aggression, which would have complicated the group housing that we consider to be an essential aspect of the study design. Procedures were approved by the ethical research committee of the university.

All animals were born within an interval of 1 month and were kept in mixed genotype groups of $8-10$ females at standard laboratory conditions (12 h dark/light cycle, constant room temperature and humidity, and standard lab chow and water ad libitum). Longitudinal testing of the mice was performed on an extended battery of functional tests at the age of 3 and 12 months. The order of testing was the same at both ages. By the time of the second testing, one knock-out and two wild-type mice had died of unknown causes. All observations were performed by experimenters who were unaware of the genotype of the tested mice. Females for histological and electrophysiological recordings were taken from parallel groups.

Neuropathological examination. Cervical spinal cord, cerebellum, brainstem, and forebrain and trigeminal ganglion, spiral, and vestibular ganglia were regularly investigated in knock-out and age-matched wildtype mice (ages 2, 6, and 9 months; taken from parallel test groups) by light microscopy (LM) (semithin sections) and in a few animals by electron microscopy (EM). Perfusion-fixed samples of brain and peripheral nervous tissues were used. Transcardial perfusion of deeply anesthetized (tribromoethanol) mice was performed with 6\% glutaraldehyde (in 0.1 phosphate buffer, $\mathrm{pH} 7.4$ ), and, for postfixation, $2 \%$ osmium tetroxide was used. The cochlea was decalcified with EDTA as described previously (Coenen et al., 2001). Tissue samples were embedded in Araldite or Epon according to standard methods. Semithin sections $(1 \mu \mathrm{m})$ were stained with toluidine blue, and ultrathin sections were stained with uranyl acetate and lead citrate.

Recording of hippocampal long-term potentiation. A group of seven female knock-outs and six wild-type females were killed at 3 months of age for in vitro LTP recordings. Hippocampal slices were prepared from these mice as described previously (Balschun et al., 1999) and immediately transferred to a submerged-type slice chamber, in which they were permanently perfused with $32^{\circ} \mathrm{C}$ artificial CSF (ACSF). After at least $1 \mathrm{~h}$ of incubation, a lacquer-coated stainless steel stimulating electrode and a glass recording electrode (filled with ACSF, 1-4 M $\Omega$ ) were placed into the stratum radiatum of the CA1 region to record field EPSPs (fEPSPs). The initial slope of the fEPSP served as a measure of this potential. Stimulation strength was adjusted to $35 \%$ of the maximum after constructing input/output curves and kept at this level throughout the experiment. During baseline recording, three single stimuli $(0.1 \mathrm{~ms}$ pulse width; $10 \mathrm{~s}$ interval) were measured every $5 \mathrm{~min}$ and averaged to $10 \mathrm{~min}$ values. Once a stable baseline had been established, weak LTP was induced by a single high-frequency stimulation (HFS) of $100 \mathrm{~Hz}$ and $400 \mathrm{~ms}$ duration $(0.2$ ms pulse width). Evoked responses were monitored at 1, 4, 7, and $10 \mathrm{~min}$ after tetanization and further as during baseline recording. A second tetanus consisting of a single theta-burst stimulation (TBS) (10 burst of four stimuli at $100 \mathrm{~Hz}$, separated by $200 \mathrm{~ms}, 0.2 \mathrm{~ms}$ pulse width) was applied $2 \mathrm{~h}$ after the first tetanization. Potentiation was pursued for $2 \mathrm{~h}$ according to the same schedule as described above. In all experiments, the recording of slices from mutant mice was interleaved by experiments with wild-type controls.

Basic afferent and neuromotor tests. Brainstem auditory-evoked potentials (BAEPs) were recorded on a Myos 4 plus digital EMG/EP recorder (Schwarzer, Munich, Germany). Mice were anesthetized with pentobarbital $(60 \mathrm{mg} / \mathrm{kg}$, i.p.) and placed in a plastic restrainer allowing reproducible placement of the electrodes and speaker. A needle electrode was placed above each ear and referenced to a common electrode near the base of the tail; a fourth electrode, also placed near the base of the tail, was used as a ground. Robust five-peak tracings were obtained by averaging 2000 responses evoked by $85-86$ dB clicks [measured with a Brüel \& Kjær (Norcross, GA) sound intensity meter] emitted by a speaker placed $1 \mathrm{~cm}$ in front of the animal's head. For each of the tracings, latencies of the first five peaks (numbered I through V) were measured as well as interpeak latencies I-III, III-V, and I-V, and V/I amplitude ratio. Because this procedure involved anesthesia and placement of needle electrodes with some risk of complication, only a subset of animals was tested.

Neuromotor testing consisted of tests for grip strength, motor coordination, and cage activity. Grip strength was measured using a device consisting of a T-shaped bar connected to a digital dynamometer (Ugo Basile, Comerio, Italy). Mice were placed before the bar, which they usually grabbed spontaneously, and gently pulled backwards until they released the bar (maximal readouts were recorded). Ten such measurements were obtained for each animal. Motor coordination and equilibrium was tested on an accelerating rotarod (Med Associates, St. Albans, VT). Mice were first trained at constant speed ( $4 \mathrm{rpm}, 2 \mathrm{~min}$ ) before they started with four test trials (intertrial interval, $10 \mathrm{~min}$ ). During these test trials, the animals had to balance on a rotating rod that accelerated from 4 to $40 \mathrm{rpm}$ in $5 \mathrm{~min}$, and time until they dropped from the rod was recorded (up to the $5 \mathrm{~min}$ cutoff). Cage activity was recorded using a lab-build activity logger connected to three infrared (IR) photo beams. Mice were put separately in $20 \times 30 \mathrm{~cm}^{2}$ transparent cages, placed between the photo beams, and activity was expressed as beam crossings for each $30 \mathrm{~min}$, during a $24 \mathrm{~h}$ interval. 
Exploratory tests. Open field exploration was examined using a $50 \times 50$ $\mathrm{cm}^{2}$ square arena. Each animal was dark adapted for $30 \mathrm{~min}$ and placed in the arena for $10 \mathrm{~min}$. Movements of the mice in the arena were recorded using EthoVision video tracking equipment and software (Noldus, Wageningen, The Netherlands). Total path length and corner crossings were included as measures of locomotor activity. These measures are highly correlated and mainly indicate thigmotactic walking near the walls of the arena. Entries into the center of the field were included as a measure of conflict resolution or anxiolysis.

The same arena was also used to assess social and dark box exploration. In the social exploration test, a round wire cage with two female mice was placed in the center of the arena. Latency of the first approach and number of approaches during the $10 \mathrm{~min}$ exploration trial were used as measures of social exploration. In the dark box test, a $10 \times 50 \mathrm{~cm}^{2}$ box with three entry holes was placed along one of the walls of the arena. The number of box entries and time spent in the box were used as exploratory measures.

The elevated plus maze was used as a test for anxiety-related exploration. The arena consisted of a plus-shaped maze with two arms $(5 \mathrm{~cm}$ wide) closed by side walls and two arms without walls. Mice were placed at the center of the maze and were allowed to explore freely for $10 \mathrm{~min}$. Exploratory activity was recorded by five IR beams (four for arm entries and one for open arm dwell) connected to a computerized activity logger.

Learning and memory tests. Passive avoidance learning was tested in a step-through box. During training, dark-adapted mice were put in the small illuminated compartment of the box. After $5 \mathrm{~s}$, a sliding door to the larger dark compartment was opened, and entry latency was recorded. The door was closed as soon as all four feet were on the grid floor, and a slight footshock $(0.3 \mathrm{~mA}, 1 \mathrm{~s})$ was delivered using a constant current shocker (Med Associates). Retention was tested $24 \mathrm{~h}$ later using the same procedure, and entry was recorded up to $300 \mathrm{~s}$ cutoff. This test was only performed in the oldest animals.

Spatial learning was tested in the Morris-type water maze with hidden platform (Stewart and Morris, 1993). We used a $150 \mathrm{~cm}$ circular pool filled with water, opacified with nontoxic white paint, and kept at $26^{\circ} \mathrm{C}$. A $15 \mathrm{~cm}$ round platform was hidden $1 \mathrm{~cm}$ beneath the surface of the water at a fixed position. Each daily trial block consisted of four swimming trials (15 min, intertrial interval) starting randomly from each of four starting positions. Mice that failed to find the platform within 2 min were guided to the platform. They had to remain on the platform for $15 \mathrm{~s}$ before they were returned to their cages. Each session of five trial blocks was followed by $2 \mathrm{~d}$ of rest and a probe trial. During these probe trials, the platform was removed from the pool, and the search pattern of the mice was recorded for $100 \mathrm{~s}$. During the last session, at 12 months of age, the position of the platform was changed to the opposite quadrant of the pool (i.e., reversal training). Swimming paths of the animals were recorded using EthoVision video tracking equipment and software (Noldus).

Odor discrimination conditioning was tested with a procedure adapted from Bunsey and Eichenbaum (1996). This test depends on olfactory discrimination as well as the ability to associate specific odor cues with an appetitive reinforcement. Briefly, mice were put on a food restriction schedule ( $1 \mathrm{~h}$ of feeding per $24 \mathrm{~h}$ ) for $4 \mathrm{~d}$ before training, which reduced their body weight by $10-20 \%$. Food restriction was continued throughout, but body weight was monitored daily to prevent it from dropping below $80 \%$ of the initial value. First, they were shaped to dig for a sweetened food reward in a sand-filled vial $(3 \mathrm{~cm}$ diameter). Starting from putting the reward on top of the sand, the task became gradually more challenging until they reached criterion (i.e., retrieving the reward from the bottom of the vial within $60 \mathrm{~s}$ ). Next followed 14 discrimination trials, during which they were presented two similar vials filled with sand scented with two different odor solutions [pure aqueous solutions of blossom and citrus odor were obtained from Sensient Flavors (Heverlee, Belgium)]. For each animal (assigned randomly to the blossom or citrus group), only one particular odor was associated with the reward [conditioned stimulus (CS+)], and rewards were randomly presented left or right. As a final cognitive challenge, eight reversal trials followed, during which the CS+ odor was reversed for each animal (e.g., a mouse trained on citrus during discrimination training now obtained its reward only from the blossom-scented vial). During each trial, digging in the separate vials was timed up to 300 s cutoff.

At the age of 12 months, instrumental learning and unconditioned and conditioned emotional responding were tested in operant cages for mice (Coulbourn Instruments, Allentown, PA). Mice were put on a food restriction schedule as above and trained in daily trials ( $30 \mathrm{~min} /$ trial) by gradual shaping to use a nose poke device to obtain food pellets (Noyes precision pellets; Research Diets, New Brunswick, NJ). Mice received food rewards during all trials throughout the experiment, but the reinforcement schedule was gradually changed to arrive at a stable response rate. Training started with seven continuous reinforcement trials (i.e., every nose poke was rewarded), followed by 12 fixed ratio (FR) trials, comprising six FR5 and six FR10 trials (respectively, 5 and 10 nose pokes for a single reward). The training ended with nine variable interval (VI) trials, VI30s (i.e., an average interval of $30 \mathrm{~s}$ between rewards), to further stabilize response rates. Rate of nose poking was recorded on each trial.

After these training trials, an adapted conditioned emotional response (CER) procedure was superimposed on the VI30s reinforcement schedule. In eight daily CER trials, $0.2 \mathrm{~mA}$ shocks were presented with a variable 3 min interval, whereas nose poking continued to be reinforced on a VI30s schedule. Shocks were signaled by $2 \mathrm{~s}$ tones, which coterminated with the $0.2 \mathrm{~s}$ shock. Rate of nose poking during these signal-and-shock trials was measured as an index of reactive response suppression (i.e., unconditioned emotional responding). Finally, auditory signals were no longer followed by shock during four final trials, and nose poke suppression in the absence of the shocks was again recorded (i.e., conditioned emotional responding).

Statistics. Data are presented as mean and SEM. Differences between groups were examined using unpaired two-tailed $t$ tests, Wilcoxon matched-pairs signed rank test, or ANOVA procedures with Fisher's least significant difference test for post hoc comparison. Significance levels were at $p<0.05$ (values of $p<0.10$ were sometimes used to indicate statistical trends). Power of the performed tests was often below the desired 0.8 value with the present sample size and subtlety of some deficits, and negative findings should be interpreted with caution. Functional overlap between some tests in the battery did, however, replicate certain observations, as will be mentioned in Discussion.

\section{Results}

\section{General appearance and neuropathology}

Fur and general physical appearance were very similar in the $\alpha$-mannosidase knock-out mice and their wild-type littermates, and an uninformed animal technician was unable to distinguish between the different mice in the mixed genotype groups. On closer inspection, knock-outs between 2 and 3 months of age were slightly lighter than age-matched controls (mean body weight, $23.2 \pm 0.4$ vs $21.5 \pm 0.5 \mathrm{~g}$ in knock-outs; $p=0.03$ ), but at $4-5$ months $(24.0 \pm 0.4 \mathrm{~g}$ in wild types vs $23.7 \pm 0.5 \mathrm{~g}$ in knockouts) and 11-12 months (25.6 $\pm 0.4 \mathrm{~g}$ in wild types vs $24.7 \pm 0.6$ in knock-outs), body weights were not significantly different. Pinna, cornea, righting, and tail-flick reflexes were vigorously present in all knock-outs.

The occurrence of clear cytoplasmic vacuoles was a common, salient feature in neurons of knock-out mice (Fig. 1) but less frequently in their astrodendroglia and oligodendroglia. At the ultrastructural level, the vacuoles showed a limiting membrane and contained small amounts of granular or filamentous material. Although evident throughout the brain, vacuolation was most evenly distributed in the neuronal perikarya of the hippocampal regions CA2 and CA3 (Fig. $1 A, B$ ), whereas the neurons of CA1 and dentate gyrus were weakly or not at all affected. In the neocortex, the neurons were vacuolated to variable degrees (Fig. 1C,D). There was no obvious age-dependent progression.

Furthermore, lateral globus pallidus contained several vacuolated neurons. In brainstem, some vacuolated neurons were seen in several nuclei, such as substantia nigra, inferior olive, am- 
biguus nucleus, cuneate and gracile nuclei, and several nuclei in formatio reticularis. In cerebellar cortex, moderate vacuolation was seen at the EM level in Purkinje cells and some granular cells. Spinal cord neurons, inspected by LM, showed weak alterations. In the peripheral nervous system, marked vacuolation was seen in trigeminal ganglion neurons and slightly less severe in the spiral and vestibular ganglion neurons. The sensory epithelia of the Corti organ and the vestibular organ appeared unaltered, whereas moderate vacuolation was seen in fibrocytes of the spiral ligament and in the nonspecialized flat epithelia lining the endolymphatic spaces of the cochlea and vestibular apparatus.

Additionally, axonal spheroids were relatively frequent in brainstem (particularly in the gracile and cuneate nuclei) and white matter of the forebrain (such as corpus callosum, external and internal capsule, hippocampal fimbria, and stria terminalis). Similar axonal spheroids were occasionally observed (but not systematically investigated) in preterminal portions of the vestibular nerve and the trigeminal nerve fibers associated with sinus hairs.

\section{Hippocampal long-term potentiation}

LTP was examined in the CA1 region of hippocampal slices from knock-out and wild-type females. First, LTP was induced by a single HFS ( 40 pulses at $100 \mathrm{~Hz}, 0.2$ ms pulse width). This type of tetanization generated a similar decremental LTP in both groups (Fig. 2), but the potentiation was marginally stronger in the knock-out group. In contrast to wild-type animals, in which fEPSP slopes returned to baseline levels after $\sim 90 \mathrm{~min}$, mutants still showed a significant potentiation after $120 \mathrm{~min}$ (compared with baseline; $p<0.05$, Wilcoxon's test). Two hours after the first tetanization, a second tetanization consisted of a single TBS ( 10 burst of four stimuli at $100 \mathrm{~Hz}$, separated by $200 \mathrm{~ms}, 0.2 \mathrm{~ms}$ pulse width). In response to TBS (Fig. 2, right), knock-out mice displayed a markedly higher initial LTP magnitude compared with wild types $(p<0.05)$ and maintained this difference throughout the recording $(p<0.05$, repeated-measures ANOVA).

\section{Basic afferent and neuromotor functions}

Although some neuropathological alterations were observed in relevant neural tissues, our cohort of $\alpha$-mannosidase-deficient mice showed no evidence of gross impairment in either of the basic afferent and neuromotor functions examined.

Neuropathological examination demonstrated slight to moderate vacuolation in brainstem and spiral ganglion neurons (Fig. $3 A-C)$. Consequently, BAEPs were tested in six knock-out mice

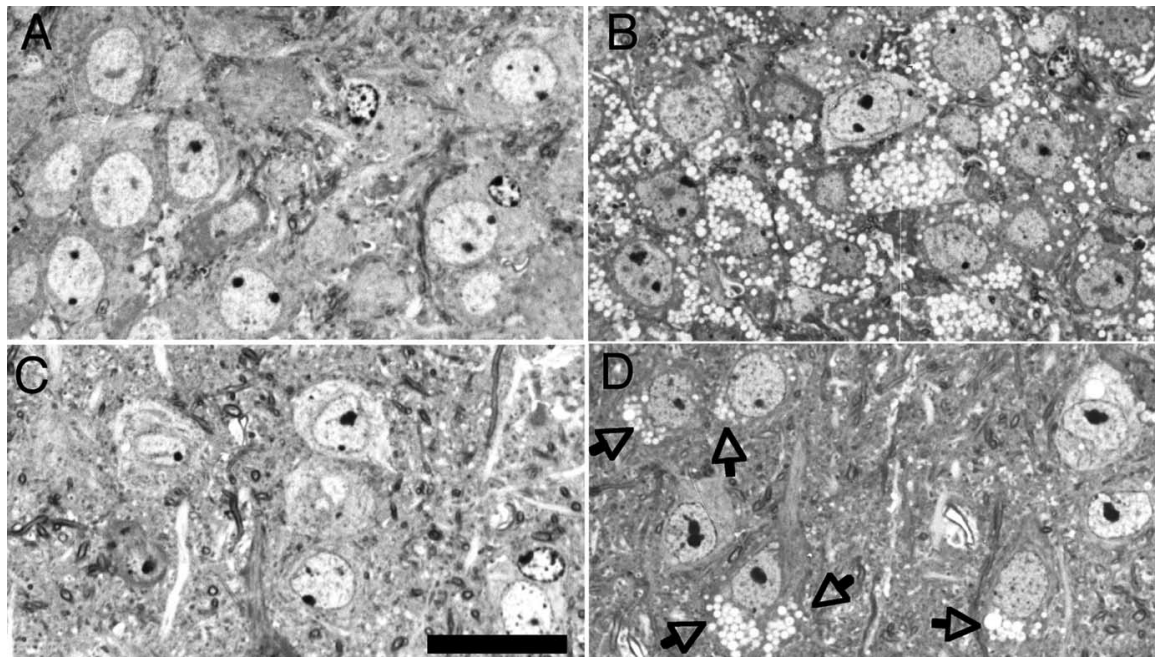

Figure 1. Light micrographs demonstrate lysosomal storage in the CNS of $\alpha$-mannosidase-deficient mice. Micrographs show the hippocampal CA3 region $(\boldsymbol{A}, \boldsymbol{B})$ and lamina $5 / 6$ neocortex $(\boldsymbol{C}, \boldsymbol{D})$ in 2-month-old wild-type $(\boldsymbol{A}, \boldsymbol{C})$ and $\alpha$-mannosidase-deficient $(\boldsymbol{B}, \boldsymbol{D})$ mice. In the hippocampal $(\mathrm{A} 3$ region $(\boldsymbol{B})$, most neuronal perikarya show clear cytoplasmic vacuoles that are the morphological equivalent for lysosomal storage of mannose-rich oligosaccharides. In the neocortex (D), vacuolation of neuronal perikarya (arrows) is more variable. Semithin sections, Toluidine blue staining. Scale bar, $20 \mu \mathrm{m}$.

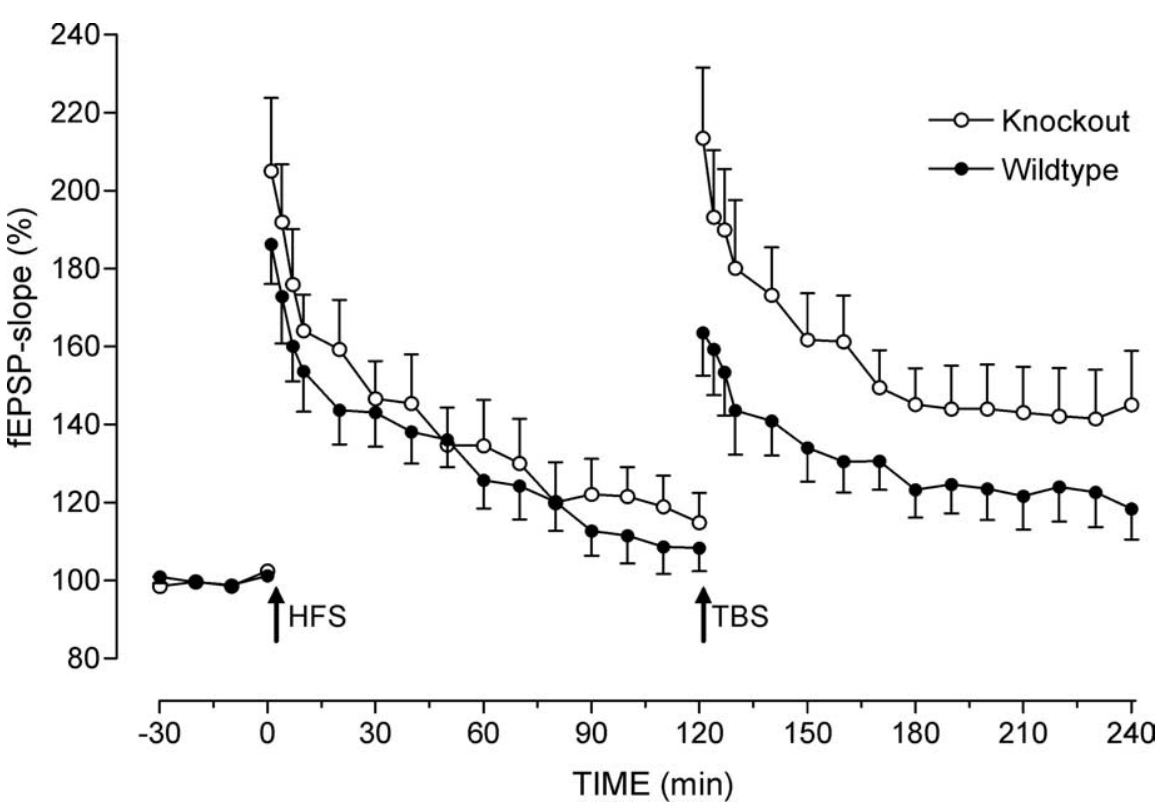

Figure 2. Hippocampal long-term potentiation in 3-month-old wild-type and $\alpha$-mannosidase-deficient mice. $\alpha$-Mannosidase-deficient mice (open circles) displayed marginally stronger LTP than wild-type littermates (filled circles), when the potentiation was induced by a single HFS but marked enhancement of potentiation in response to TBS ( 10 burst of 4 stimuli at $100 \mathrm{~Hz}$ ). Both groups generated a similar decremental LTP after HFS, but knock-outs still showed a significant potentiation after $120 \mathrm{~min}$ ( $p<0.05$, Wilcoxon's test). Knock-out mice displayed a higher initial LTP magnitude after TBS and maintained this difference throughout the recording ( $p<0.05$, repeated-measures ANOVA). Graphs show mean slopes of fEPSP and SEMs (error bars), expressed as a percentage of initial value.

and four control littermates at 3 and 12 months (Fig. 3D). All animals, except one control mouse at 3 months (not included for additional analysis), showed a typical five-peak pattern in their BAEP responses. Latency of the peaks was robust and very similar in knock-outs and wild-type littermates (Fig. 3, bottom). Statistical analysis (repeated-measures ANOVA) revealed no difference in mean peak latency between knock-out mice and controls, at either age. Analysis of interpeak latencies and V/I amplitude ratio also failed to show any significant difference between the genotype or age groups tested. It should also be noted that V/I 

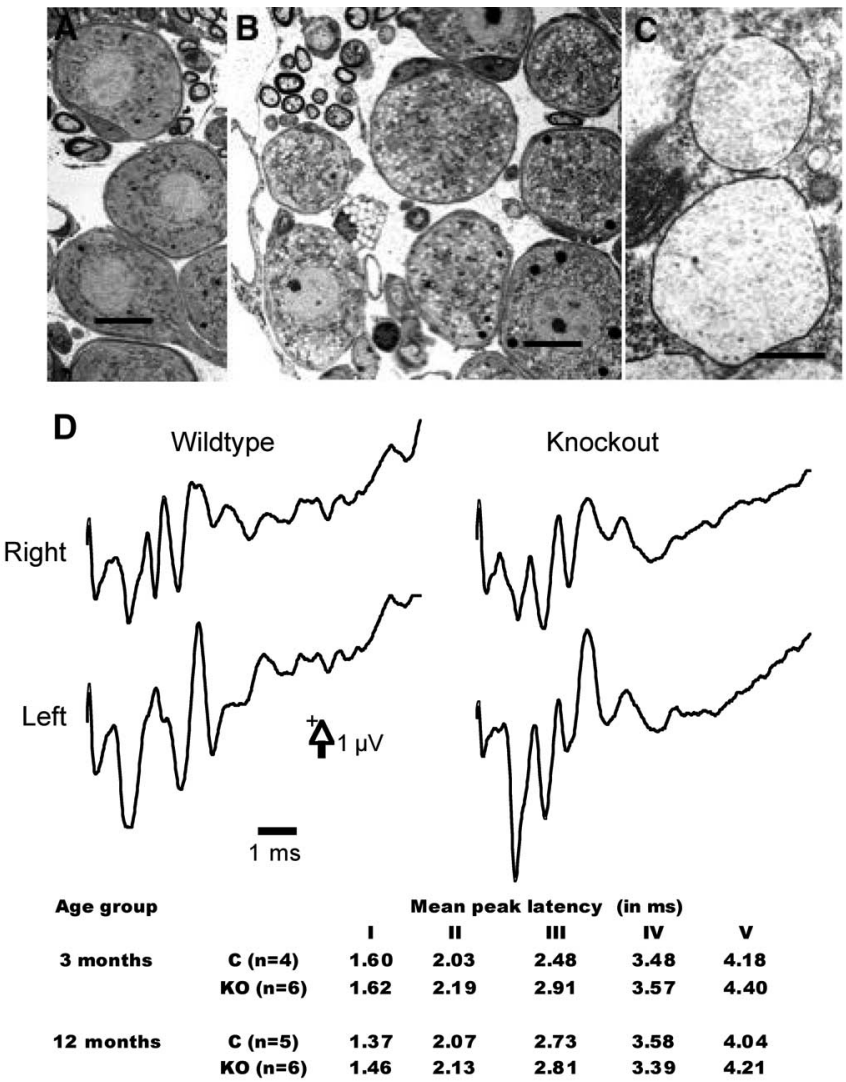

Figure 3. Electron micrographs of spiral ganglia and auditory-evoked potentials in wildtype and $\alpha$-mannosidase-deficient mice. Electron micrographs of spiral ganglia in a 6-monthold wild-type $(\boldsymbol{A})$ and a 2 -month-old $\alpha$-mannosidase-deficient $(\boldsymbol{B})$ mouse demonstrate lysosomal storage in the deficient animal. Two vacuoles from a spiral ganglion cell at a higher resolution show the limiting membrane and the low amounts of granular contents (C). Most of the storage material is artificially leached during tissue preparation. Scale bars: $A, B, 10 \mu \mathrm{m} ; C$, $0.5 \mu \mathrm{m}$. Brainstem auditory-evoked potentials, conversely, show no difference between wildtype and $\alpha$-mannosidase-deficient mice at either age (D). Examples shown in this figure are from a 3-month-old control and knock-out mouse (left and right ears). The table at the bottom of the figure shows mean latency for each of the five peaks that were identified in the left or right ear recordings of the tested mice.

Table 1. Neuromotor assessment in 3- and 12-month-old wild-type and $\alpha$-mannosidosis mice

\begin{tabular}{|c|c|c|c|}
\hline & & 3 months & 12 months \\
\hline \multirow[t]{6}{*}{ Grip strength (in mN) } & & $630 \pm 20^{a}$ & $592 \pm 31^{a}$ \\
\hline & \multirow{3}{*}{ Median of 10 trials } & $626 \pm 21^{b}$ & $566 \pm 28^{b}$ \\
\hline & & $623 \pm 14^{a}$ & $641 \pm 27^{a}$ \\
\hline & & $612 \pm 18^{b}$ & $591 \pm 40^{b}$ \\
\hline & \multirow[t]{2}{*}{ Maximum of 10 trials } & $830 \pm 7^{a}$ & $841 \pm 27^{a}$ \\
\hline & & $824 \pm 18^{b}$ & $831 \pm 17^{b}$ \\
\hline \multirow[t]{2}{*}{ Accelerating rotarod (time on rod) } & \multirow[t]{2}{*}{ LSM of 4 trials (in seconds) } & $243 \pm 13^{a}$ & $219 \pm 13^{a}$ \\
\hline & & $243 \pm 12^{b}$ & $208 \pm 11^{b}$ \\
\hline \multirow[t]{2}{*}{ Locomotion in home cage (beam crossings) } & & $11,031 \pm 1443^{a}$ & $11,082 \pm 1142^{a}$ \\
\hline & & $9652 \pm 862^{b}$ & $9695 \pm 1103^{b}$ \\
\hline
\end{tabular}

All values are means \pm SEM. LSM, Least square means.

${ }^{a}$ Measures in control mice.

${ }^{b}$ Differences between means are not significant.

ratio hardly changed in knock-out mice between 3 months $(0.82 \pm 0.14)$ and 12 months $(0.8 \pm 0.4)$.

Motor nuclei in brains of $\alpha$-mannosidase-deficient mice showed little neuropathological alterations (data not shown). Grip strength, accelerating rotarod, and locomotion in the home cage were very similar in both genotypes and did not show any age-related alterations (Table 1). Analysis of the circadian activity in the home cage also showed no significant effect between the genotypes (Fig. 4). The initial increase in exploratory activity recorded during introduction of animals into their cages was slightly lower in knock-out mice, but repeated-measures ANOVA revealed no effect of genotype or of genotype $\times$ time interaction on mean cage activity measures registered during a $24 \mathrm{~h}$ recording.

\section{Exploratory test performance}

Several of the exploratory tests included in this assessment revealed slight but rather consistent differences in exploratory activity between knock-out and wild-type littermates. Several of these tests are known to be sensitive to effects of handling of the animals or of repeated exposure to the test environment, and additional examination of this exploratory deficit still seems warranted. However, the present results indicate that the observed deficit does not aggravate with increasing age of the animals.

Most typically, open field activity showed mild but consistent effects of genotype. Both path length and the number of corner crossings during the $10 \mathrm{~min}$ recording period were lower in knock-outs compared with wild-type controls (Fig. 5). In both age groups, two-way ANOVA revealed slight but significant effects of genotype on path length $\left(F_{(1,52)}=4.9 ; p=0.03\right)$ and corner crossings $\left(F_{(1,52)}=6.7 ; p=0.01\right)$. Notably, neither of these two measures showed any effect of age or of genotype $X$ age interaction (all $p>0.3$ ). Entries into the center of the field were also not significantly different between the genotype groups.

In addition, several variants of the open field test were included (Table 2). Results of the social exploration test indicated a slight decrease in exploratory activity in the knock-out group (borderline significant at $p<0.1$ ), but age/repetition effects influenced these observations. Two-way ANOVA indeed revealed considerable effects of age on mean number of approaches $(p=$ $0.01)$ and latency of the first approach $(p=0.001)$, which could be attributable to the age of the mice as such or to their repeated exposure to the testing environment. Results of the dark box exploration test further confirmed a decrease in exploratory activity in the knock-out mice because the number of box entries was significantly decreased in the knockout mice $\left(F_{(1,29)}=7.5 ; p=0.01\right)$.

In addition to decreased path length and corner crossing in the open field test, results of the dark box test showed that the knock-outs stayed longer in the box than their wild-type littermates $\left(F_{(1,29)}=5.2\right.$; $p=0.03)$. This decrease in exploratory or ambulatory activity appeared not to be attributable to increased levels of anxiety because knock-outs did not explore the center of the open field less often than their wildtype littermates $\left(F_{(1,52)}=1.1 ; p>0.3\right)$. The elevated plus maze, the prototypical test for anxiety, even showed a slight increase in time spent by 12 -month-old knock-outs in the open arms of the maze (Table 2) (borderline significant at $p<0.1)$.

\section{Cognitive abilities}

Several learning and memory tests included in this assessment indicated impaired cognitive performance in the knock-outs as well. However, no indication was found of a prominent deterioration of learning and memory abilities with increasing age.

Because the step-through task is typically a test for single-trial 
passive avoidance learning, only the 12month-old mice were subjected to this test (Table 2, bottom row). During the training trial, knock-out mice entered into the dark compartment just as quickly as their wild-type littermates. During the testing trial, conversely, nearly all of the wild-type mice avoided entrance into the dark compartment during the $300 \mathrm{~s}$ observation period, whereas several knock-outs did enter during this time. Consequently, stepthrough latency was slightly but significantly reduced in the knock-out group.

The water maze test for spatial learning and memory is obviously a much more elaborate procedure, and we trained and retrained our mice in this arena at 3 and 12 months of age (Figs. 6, 7). The task was subdivided in four acquisition and retention test sessions. Each session consisted of five daily acquisition trial blocks, followed by $2 \mathrm{~d}$ of rest, and a final retention test (probe trial). Two such acquisition and probe trial sessions were administered at 3 months (Fig. 6) and two sessions at 12 months (Fig. 7). During the first three acquisition training sessions, the escape platform remained at the same position, but it was moved to the opposite quadrant for the last acquisition session in the 12month-old mice (i.e., reversal training).

During all acquisition sessions, the knock-out group consistently reached the platform slightly later than their wild-type littermates. This difference was much smaller in 12-month-old than in 3-month-old mice and was, in fact, not significant when analyzed with repeatedmeasures ANOVA. At 3 months of age, two-way ANOVA did, however, indicate a significant effect of genotype on mean escape latency during all acquisition trial blocks $\left(F_{(1,290)}=11.7 ; p<0.001\right)$. Compared with wild types, overall escape latency was $26.3 \%$ lower in 3-month-old knock-outs but only $12.2 \%$ lower in 12 month-old knock-outs. Notably, during the last acquisition session in 12-monthold mice (reversal training), repeatedmeasures ANOVA did not show a significant effect of genotype $(p=0.2)$.

The probe trials after each acquisition session indicated most clearly the difference in water maze performance between knockout and wild-type littermates. The most dramatic effect was found during the first probe trial in the 3-month-old group (Fig. 6 , probe 1). Knock-out mice displayed a search pattern that was very different from wild types, which was demonstrated by a significant effect of genotype $\times$ quadrant interaction on mean percentage of search time spent in the different quadrants of the pool $\left(F_{(3,116)}=4.5 ; p=0.003\right)$. Also, 3-month-old knock-outs crossed the target area on average only $2.5 \pm 0.6$ times compared with $4.6 \pm 0.7$ times in wild types $(p<0.05)$. The animals were placed in the pool at the center of the opposite quadrant, and, as
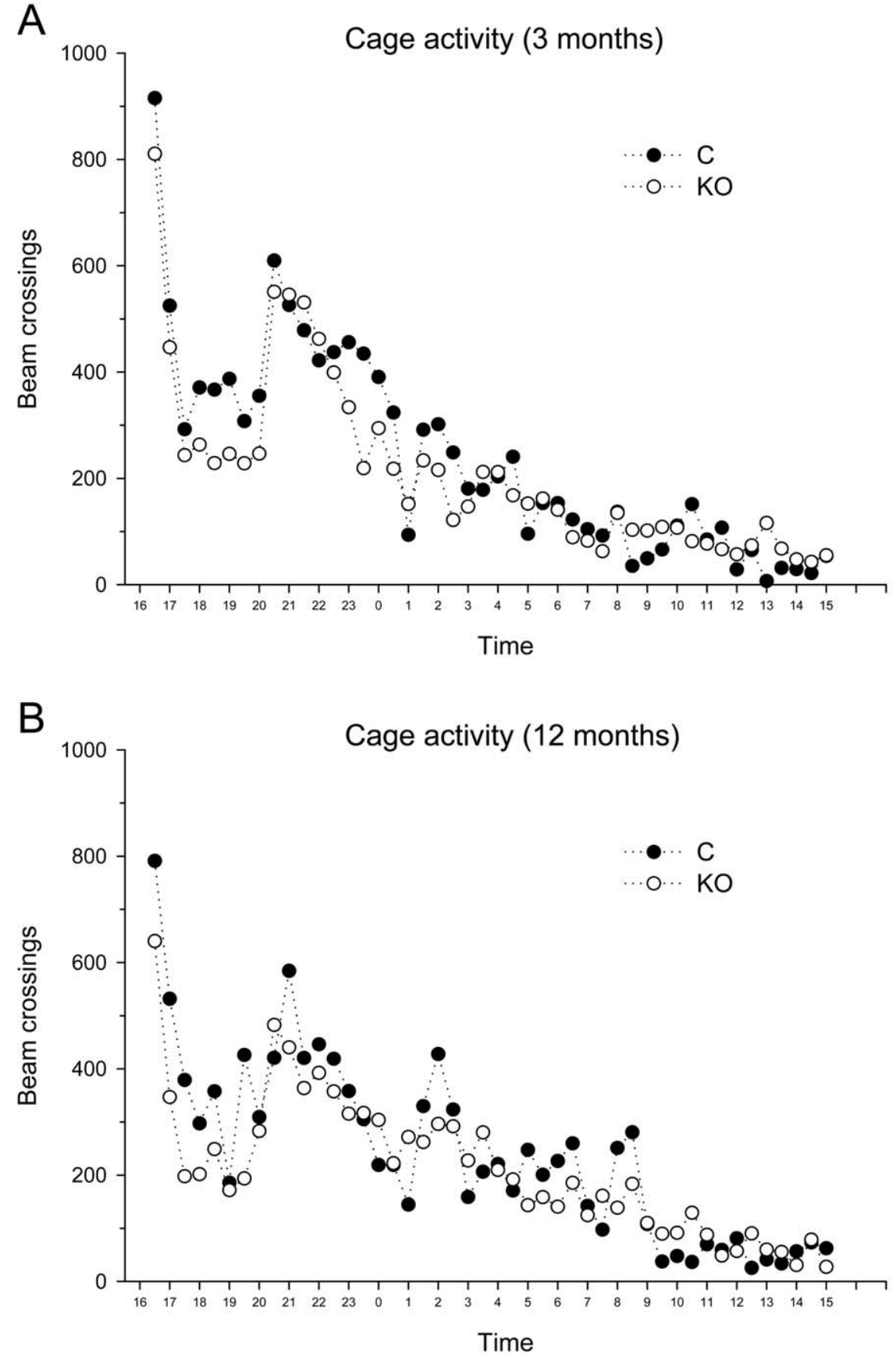

Figure 4. Mean home cage activity during a $24 \mathrm{~h}$ recording session in 3- and 12-month-old wild-type and $\alpha$-mannosidase knock-out mice. The exploratory peak recorded during introduction of animals into the cages was slightly lower in knock-out mice (open circles), but overall activity was not significantly different between the groups.

the data indicate, the knock-outs tended to remain in this start quadrant instead of searching for the platform in the other quadrants $(p=0.001)$. Three of the 17 knock-out mice actually stayed in the target quadrant all of the time, but the observed interaction effect remained significant even when these three extreme animals were eliminated from the analysis $\left(F_{(3,104)}=4.3 ; p=0.007\right)$.

During their second probe trial (Fig. 6, probe 2), some of the differences in performance between the 3-month-old knock-outs and wild types were eliminated by intervening training. Indeed, two-way ANOVA failed to reveal a significant effect of genotype $\times$ quadrant interaction on mean percentage of search time in the different quadrants $(p=0.13)$, and the number of target 

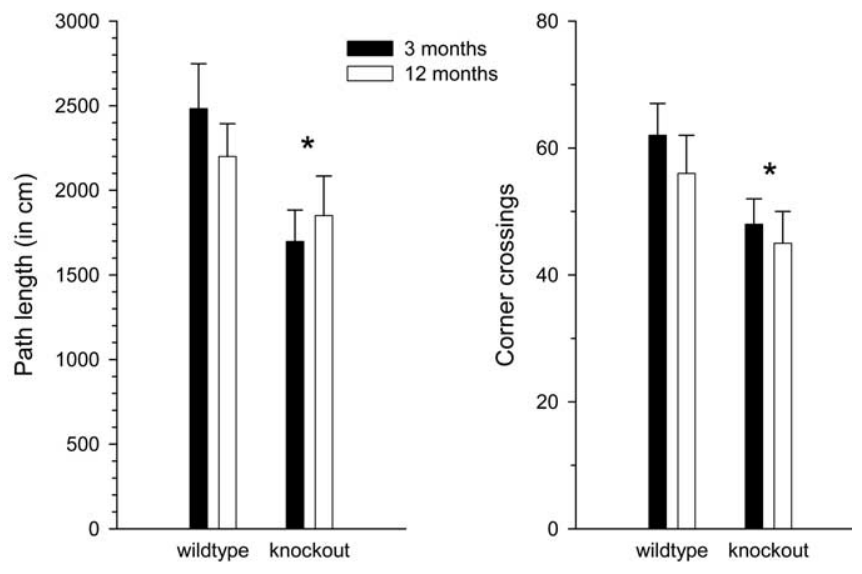

Figure 5. Open-field locomotion in 3-and 12-month-old wild-type and $\alpha$-mannosidase knock-out mice. Bars indicate mean values and SEM (error bars) in mice at 3 months (blackbars) and 12 months (white bars) of age. Both path length and corner crossings are significantly reduced in the knock-out group $\left({ }^{*} p<0.05\right)$.

entries was also not significantly different between the groups (4.6 \pm 0.7 in wild types vs $3.9 \pm 0.7$ in knock-outs; $p=0.5$ ). However, the wild-type controls did display a clear spatial preference for the target quadrant ( $p=0.013)$, whereas the knockouts did not, and actually spent equal amounts of time in target and opposite quadrant (difference, $p=0.96$ ).

The acquisition results in the 12-month-old animals showed that both groups of mice retained much of their ability to solve the maze even after a 9 month delay, and continued training further improved their performance (Fig. 7). During their subsequent probe trial (Fig. 7, probe 1), the 12-month-old mice now displayed clear spatial preference for the target quadrant. Still, several measures did indicate less accurate performance in knock-outs. There was a highly significant effect of genotype $\times$ quadrant interaction on mean percentage of search time in the different quadrants $\left(F_{(3,104)}=5.9 ; p<0.001\right)$, and the knockouts spent significantly less time in the target quadrant than controls $(p=0.007)$. Also, knock-outs crossed the target area $4.3 \pm$ 0.6 times compared with $6.5 \pm 0.7$ times in controls $(p=0.02)$, and knock-outs remained on average $38.4 \pm 1.7 \mathrm{~cm}$ removed
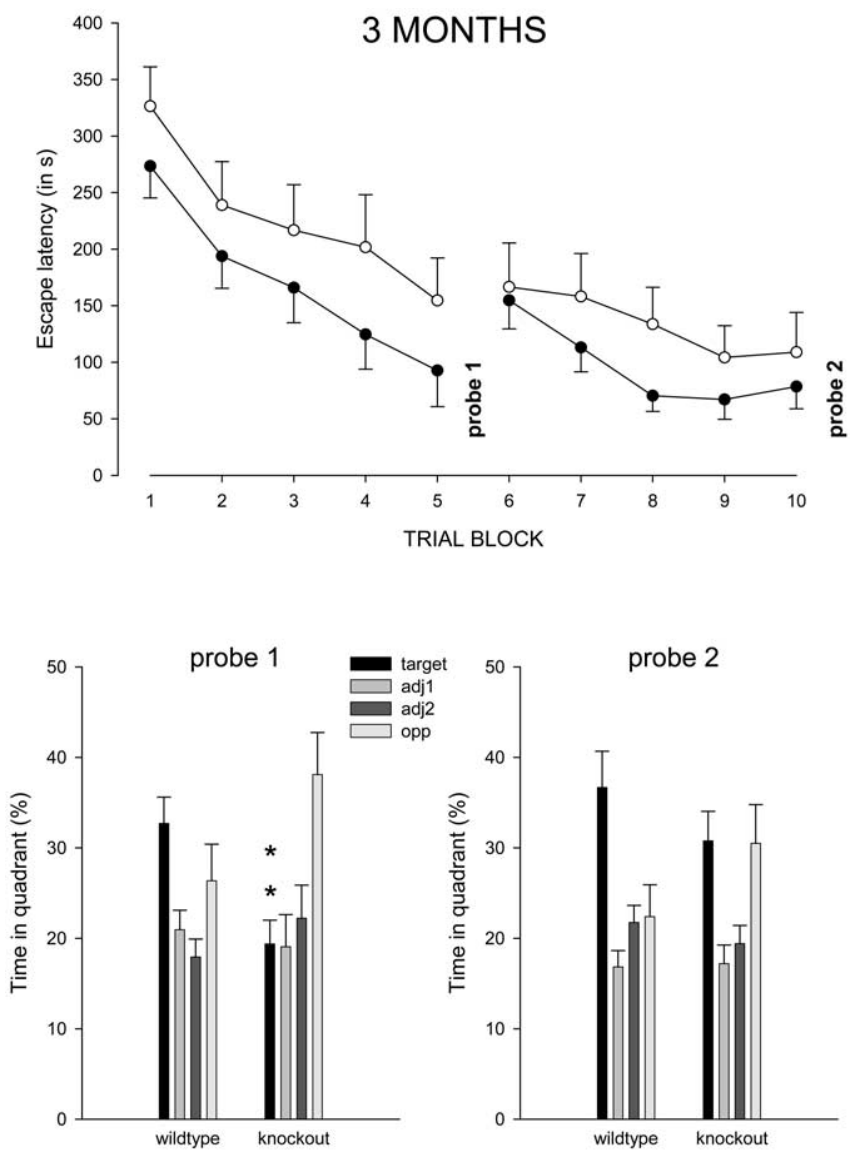

Figure 6. Water maze performance in 3-month-old wild-type and $\alpha$-mannosidase knockout mice. Acquisition of the task (top part of the figure) consisted of 10 trial blocks with a probe trial after each five blocks (probe 1 and probe 2). The escape platform remained in the same position on all acquisition trial blocks. Plots show mean escape latency (and SEM) for wild-type (filled circles) and knock-out (open circles) mice. Escape latency was consistently longer in the knock-outs on all trials blocks, but differences were smaller toward the end of training. Bottom part of the figure shows mean percentage of time (and SEM) spent in each of the four pool quadrants (i.e., target, adjacent 1 and 2, and opposite quadrant) during probe trial 1 and 2 . Knock-outs search significantly less in the target quadrant (black bars) during probe 1 (**p $<$ 0.01 ) but not during probe 2 . However, knock-outs still spent equal amounts of time in the target and opposite quadrant during probe 2.

Table 2. Exploratory tests and passive avoidance learning in 3- and 12-month-old wild-type and $\alpha$-mannosidosis mice

\begin{tabular}{|c|c|c|c|c|}
\hline & & 3 months & 12 months & Significance of differences \\
\hline \multirow[t]{4}{*}{ Social exploration } & \multirow[t]{2}{*}{ Approaches } & $14.4 \pm 3.9^{a}$ & $30.8 \pm 3.1^{a}$ & \\
\hline & & $14.4 \pm 3.7$ & $18.1 \pm 2.3$ & Two-way ANOVA, age effect; $p=0.01$ \\
\hline & \multirow[t]{2}{*}{ Latency of 1st approach (in seconds) } & $220 \pm 62^{a}$ & $31 \pm 13^{a}$ & \\
\hline & & $214 \pm 52$ & $93 \pm 29$ & Two-way ANOVA, age effect; $p=0.001$ \\
\hline \multirow{4}{*}{ Dark box exploration } & \multirow[t]{2}{*}{ Entries } & $27.0 \pm 5.1^{a}$ & & \\
\hline & & $12.2 \pm 2.6$ & & $p<0.01$ \\
\hline & \multirow[t]{2}{*}{ Time inside box (in seconds) } & $784 \pm 74^{a}$ & & \\
\hline & & $987 \pm 53$ & & $p<0.05$ \\
\hline \multirow[t]{4}{*}{ Elevated plus maze } & \multirow[t]{2}{*}{ Total beam crossings } & & $138 \pm 11^{a}$ & NS \\
\hline & & & $117 \pm 10$ & \\
\hline & \multirow[t]{2}{*}{ Percentage of time in open arms } & & $21.3 \pm 2.2^{a}$ & $p=0.095^{b}$ \\
\hline & & & $25.9 \pm 1.6$ & \\
\hline \multirow[t]{4}{*}{ Step-through task } & \multirow[t]{2}{*}{ Latency during training (in seconds) } & & $10 \pm 2^{a}$ & NS \\
\hline & & & $21 \pm 9$ & \\
\hline & \multirow[t]{2}{*}{ Latency during testing (in seconds) } & & $295 \pm 3^{a}$ & $p<0.05$ \\
\hline & & & $219 \pm 32$ & \\
\hline
\end{tabular}

All values are means \pm SEM. Significance of differences between means are indicated in the right column. 

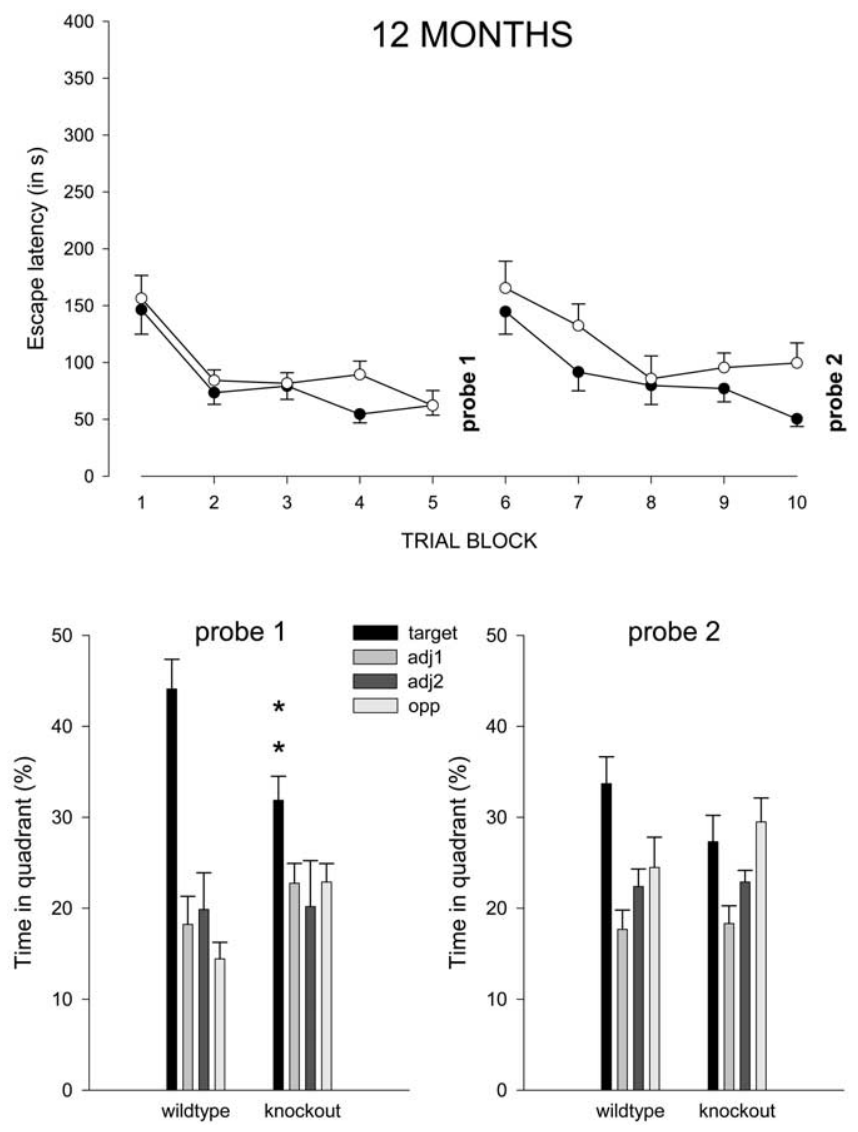

Figure 7. Water maze training continued in 12-month-old wild-type and $\alpha$-mannosidase knock-out mice. Acquisition of the task (top part of the figure) consisted of 10 trial blocks with a probe trial after each five blocks (probe 1 and probe 2). The escape platform was in the same position as during the 3 -month testing during trial blocks $1-5$ but was changed to the opposite quadrant during blocks 6-10 (reversal trials). Plots show mean escape latency (and SEM) for wild-type (filled circles) and knock-out (open circles) mice. Escape latency was now only slightly longer in the knock-outs. The bottom part of the figure shows mean percentage (and SEM) of time spent in each of the four pool quadrants (i.e., target, adjacent 1 and 2, and opposite quadrant) during probe trials 1 and 2. Knock-outs search significantly less in the target quadrant (black bars) during probe $1\left({ }^{* *} p<0.01\right.$ ) but not during probe 2 . Again, knock-outs spent equal amounts of time in the target and opposite quadrant during probe 2 .

from the target area compared with $32.2 \pm 1.7 \mathrm{~cm}$ in controls $(p=0.02)$.

During the second probe trial in 12-month-old mice (Fig. 7, probe 2), the animals were supposed to look for the platform that was opposite the former target position. The data show that this reversal was less efficient in knock-outs than controls. In fact, control animals spent most time in the new target quadrant $(p<$ 0.05 ), whereas knock-outs spent the same amount of time in the new and the former target quadrant $(p=0.6)$. Also, knock-outs remained on average $44.7 \pm 2.1 \mathrm{~cm}$ removed from the target area compared with $38.2 \pm 2.2 \mathrm{~cm}$ in controls $(p=0.05)$.

Because this is a longitudinal study, we compared water maze performances between 3- and 12-month-old animals. Notwithstanding previous experience in the oldest animals, the difference in performance between knock-outs and controls during the last acquisition session at 3 months of age (Fig. 6) was actually smaller than that during the first acquisition session in the 12-month-old animals (Fig. 7). Furthermore, as mentioned above and shown in Figure 7 (probe 2), the results of the second probe trial in the 12-month-old mice indicated a persisting difference between knock-outs and controls. Presently, one could compare their per- formance during this probe trial with the performance during the previous probe trial (also at 12 months of age) and that during the last probe trial at 3 months of age. This comparison shows that the difference in time spent in the target quadrant was not significantly different between these probe trials $(p=0.6)$. Thus, these observations do not show any obvious decline in learning abilities between knock-outs of 3 or 12 months.

During the odor discrimination task (Fig. 8), mice learned to discriminate between two odors to obtain a food reward. Before discrimination conditioning, 3-month-old animals were gradually shaped to dig for a food reward in a sand-filled vial (not shown in the figure). Although all animals eventually learned to display this behavior in a reliable way (i.e., after 32 shaping trials), time to obtain the reward was consistently longer in knock-outs (mean of 32 trials, $84.7 \pm 14.8 \mathrm{~s}$ ) compared with wild-type littermates $(52.7 \pm 16.4 \mathrm{~s} ; p<0.001)$. The ensuing discrimination conditioning showed slower acquisition in the knock-out group (Fig. 8A). Preference measures (expressed as percentage of total digging time spent digging in the CS + vial) increased during 14 discrimination trials (effect of trial, $p<0.001$ ), but repeatedmeasures ANOVA also demonstrated a significant effect of interaction genotype $\times$ trial $\left(F_{(13,338)}=1.8 ; p<0.05\right)$. During the eight reversal trials that followed discrimination conditioning, no effect was found between the genotypes.

A short shaping procedure (seven trials) was again included when the mice were retrained at 12 months (Fig. 8 B). Mean time to obtain the hidden reward was again longer in knock-outs $(109.7 \pm 19.9 \mathrm{~s})$ compared with wild-type littermates $(64.5 \pm$ $22.3 \mathrm{~s} ; p<0.001$ ), but, during the 14 discrimination trials and the eight reversal trials, no differences were found between the groups. Notably, this also indicates that performance in this test did not decrease measurably with increasing age of the knock-outs.

In the instrumental learning task (Fig. 9), animals were trained to nose poke for food pellets. Acquisition curves over 28 trials were similar in knock-outs and controls (Fig. 9A). Repeated-measures ANOVA demonstrated a highly significant effect of trial $\left(F_{(27,702)}=65.6 ; p<0.001\right)$ but neither a main effect of genotype $\left(F_{(1,26)}<1\right)$ nor a genotype $\times$ trial interaction $\left(F_{(27,702)}=1.1 ; p=0.4\right)$. Similar acquisition performance notwithstanding, rate of responding in eight subsequent trials with signaled shocks was consistently higher in knock-outs than their wild-type littermates (reflecting less unconditioned freezing in knock-outs) (Fig. 9B). For these CER trials, repeated-measures ANOVA revealed both an effect of trial $\left(F_{(7,182)}=8.9 ; p<0.001\right)$ and an effect of genotype $\left(F_{(1,26)}=6.8 ; p<0.02\right)$ without interaction $\left(F_{(7,182)}=1.1 ; p=0.35\right)$. A genotype effect was also observed in four additional trials in which signals were no longer followed by shock (conditioned freezing). Repeated-measures ANOVA again revealed main effects of trial $\left(F_{(3,78)}=25.4 ; p<\right.$ $0.001)$ and genotype $\left(F_{(1,26)}=5.8 ; p<0.03\right)$ without interaction $\left(\mathrm{F}_{3,78}<1\right)$. In line with the presence of a genotype effect during the unconditioned and conditioned emotional responding trials, but not during the instrumental acquisition, repeated-measures ANOVA over all 40 instrumental trials demonstrated a significant genotype $\times$ trial interaction $\left(F_{(39,1014)}=1.43 ; p<0.05\right)$.

\section{Discussion}

We presented a functional assessment in $\alpha$-mannosidasedeficient mice that display similar neuropathological alterations to human $\alpha$-mannosidosis. In the CNS of $\alpha$-mannosidosis patients, neuronal storage is evidenced by ballooning of neuronal perikarya and occurrence of storage vacuoles (Sung et al., 1977). 
A

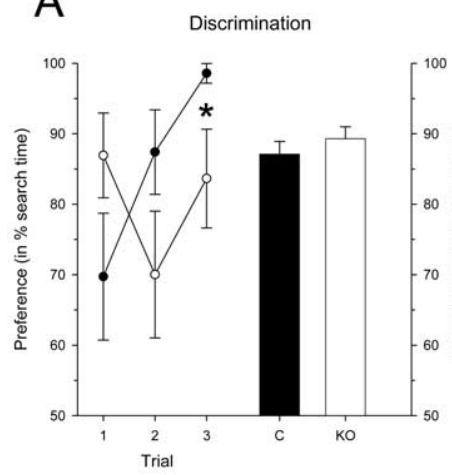

B

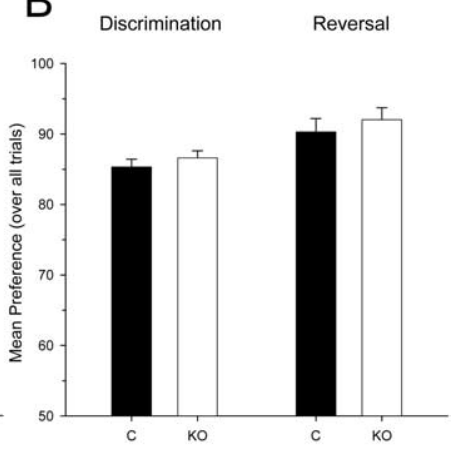

Figure 8. Odor discrimination conditioning in 3-month-old $(\boldsymbol{A})$ and 12-month-old $(\boldsymbol{B})$ wild-type and $\alpha$-mannosidase knockout mice. Bars depict mean preference (and SEM) in wild-type (black bars) and knock-out (white bars) mice expressed as percentage of time spent digging in the target vial. The initial discrimination trials were less consistent in the knock-outs (open circles in preference plot, $\boldsymbol{A})$, but additional training eventually stabilized their performance. Overall discriminatory and reversal performances were similar in both genotype groups (bar charts in $\boldsymbol{A}$ and $\boldsymbol{B}$ ). C, Controls; K0, knock-outs.

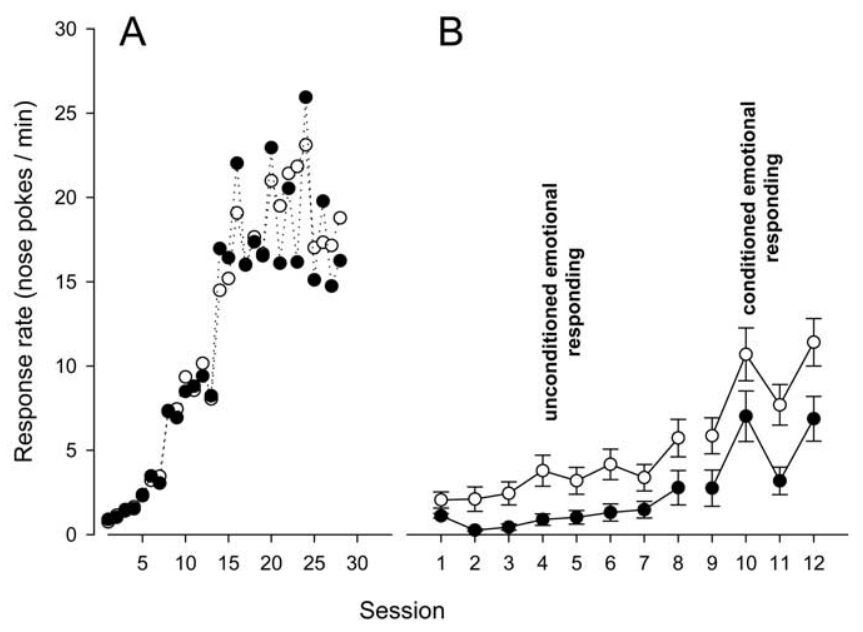

Figure 9. Appetitive conditioning and CER trials in 12-month-old wild-type and $\alpha$-mannosidase knock-out mice. During the initial training $(\boldsymbol{A})$, response rates (expressed as mean number of nose pokes per minute) gradually increased, but rates were not significantly different between wild-type (filled circles) and $\alpha$-mannosidase knock-out (open circles) mice. High response rates were displayed during the last training trials with intermittent food reinforcement. During 12 CER trials $(\boldsymbol{B})$, tone-and-shock presentations (during unconditioned emotional responding trials) and tone presentations (during conditioned emotional responding trials) are superimposed on the intermittently reinforced conditioning schedule. Response rates are severely suppressed during the CER trials, but mean response rate is consistently higher in the knock-out group during all CER trials.

Major brain regions, including neocortex, cerebellum, brainstem, and spinal cord, display neuropathological changes attributable to widespread accumulation of mannose-rich oligosaccharides. Patients present a complex and variable configuration of cognitive and behavioral alterations that may or may not deteriorate with increasing age (Thomas, 2001). The pathophysiological basis of these neuropsychological and psychopathological changes remains poorly understood, and safe and effective treatment is not available.

Mice with $\alpha$-mannosidase gene disruption were described as a valid model for the early or milder forms of $\alpha$-mannosidosis (Stinchi et al., 1999), which present more complex psychopathological features (Gutschalk et al., 2004). Hearing impairment typically develops in patients (Thomas, 2001), but, although pathological changes appeared in spiral ganglia of $\alpha$-mannosidasedeficient mice, their BAEP responses were unaffected at 3 and 12

months of age. Also, in contrast with some clinical observations, basic motor abilities were not impaired in the mice and did not deteriorate during the course of this study. It should again be noted, however, that motor impairment might be particularly prominent in the more severe forms of the disease and might be influenced by the skeletal deformations in severely affected patients (Thomas, 2001). The mice do not display obvious skeletal, postural, or gait abnormalities, and orthopedic disease seems unlikely, but we cannot completely exclude the possibility of subtle motor impairment influencing tests that rely on motor proficiency.

$\alpha$-Mannosidosis occurs in several animal species, but so far, no report has detailed the behavioral changes in the animal models. In $\alpha$-mannosidase-deficient guinea pigs, Crawley et al. (1999) reported lower body weights and a configuration of vaguely described behavioral abnormalities that included hypoactivity and an impression of progressive mental dullness. These animals also displayed marked cytoplasmic vacuolation in most central neurons, including in neocortex, hippocampus, thalamus, cerebellum, brainstem, and spinal cord (Crawley et al., 1999). Slightly lower body weights and widespread neuropathological alterations also occurred in our $\alpha$-mannosidase-deficient mice. Vacuolation was noted in hippocampus, neocortex, and various other central structures and are a common features of $\alpha$-mannosidosis, regardless of the species (Desnik et al., 1976; Sung et al., 1977; Jolly and Thompson, 1978; Cummings et al., 1988). The vacuoles are storage lysosomes, which appear almost empty because water-soluble, mannose-rich oligosaccharides are leached during tissue processing. Axonal spheroids were also obvious in $\alpha$-mannosidase-deficient mice and have been described in CNS of cats with several lysosomal storage disorders including $\alpha$-mannosidosis (Walkley et al., 1991, 1994) and in brain of cattle with $\alpha$-mannosidosis (Jolly and Thompson, 1978).

The presently available material does not allow quantitative comparison of age-dependent changes in storage neuropathology, but, even up to the age of 12-13 months (Stinchi et al., 1999), there appears to be only slight progression in the mice examined so far. Also, their behavioral and cognitive abilities did not noticeably deteriorate during the course of this longitudinal study, which is in accordance with some observations in human patients (Noll et al., 1986, 1989; Ara et al., 1999). In most lysosomal storage disorders, the molecular mechanism of the neuronal impairment is not known, and the amount of storage often correlates poorly with the neuronal dysfunction (Tardy et al., 2004). In wild-type mice, effects of aging on memory performance usually appear well beyond the age of 12 months. Enthoven et al. (2004) found no difference in probe trial performance after water maze training between backcrossed C57BL/6 females tested at 5-6 months and those tested at 14-16 months, but water maze deficits have been reported in pure C57BL/6 mice at $22-26$ months (Frick et al., 2000).

The observed water maze acquisition and probe trial deficits could be compensated by additional training, but performance was again impaired during reversal trials. This indicates that our mice have problems in changing from one learned location to the other, which could be indicative of a defect in response flexibility 
or working memory. The spatial water maze task has been introduced as an instrument with particular sensitivity to hippocampal lesions (Morris et al., 1982; Stewart and Morris, 1993). Many authors have presented evidence for the specific and disproportional involvement of the hippocampal formation in the spatial aspects of water maze learning in laboratory rodents (Brandeis et al., 1989; D’Hooge and De Deyn, 2001). Florian and Roullet (2004) specifically concluded that the hippocampal CA3 region is essential for water maze acquisition and consolidation in mice. Hippocampus-lesioned rats are also impaired in hiddenplatform learning (Wright et al., 2004), but acquisition is normal in nonspatial operant discrimination (Gallagher and Holland, 1992) or taste aversion-based discrimination (Skinner et al., 1994).

Although storage appeared throughout the CNS, disturbances in hippocampal CA3 neurons or CA3-CA1 synaptic connections might have contributed significantly to the behavioral alterations in $\alpha$-mannosidase-deficient mice. Vacuolation was especially prominent in CA3, and LTP of field potentials recorded from CA1 was enhanced. Several authors reported enhanced hippocampal LTP in cognitively impaired mice. Notably, CRND8 mice with $\beta$-amyloid deposits in hippocampus and other brain areas display enhanced LTP in different stimulation protocols and impaired acquisition and reversal learning in the water maze (Chishti et al., 2001; Jolas et al., 2002). Enhanced LTP has been shown to disrupt the normal function of hippocampal place cells (Taverna et al., 2005), which could explain spatial deficits, but Gerlai et al. (1998) showed impaired spatial as well as nonspatial learning in mutants with enhanced LTP. The results of the different tasks indicate that deficits in $\alpha$-mannosidase-deficient mice are also not restricted to spatial learning but include aversively motivated behavior in general.

Escape learning in the water maze task, passive avoidance learning, as well as emotional response conditioning were all impaired in our $\alpha$-mannosidase-deficient mice. Appetitive odor discrimination learning, conversely, was only marginally impaired during the shaping phase, whereas both the actual discrimination and reversal parts of this task were normal. Acquisition or shaping of the operant task, in which mice learned to associate nose poking with food rewards, was also unchanged. However, $\alpha$-mannosidase-deficient mice do not acquire signalshock associations as well as controls, and because the decrease in response suppression persisted during the conditioned emotional response trials, this was not attributable to decreased reactivity to shock. These alterations appear to be part of a configuration of changes that eventually impair aversively motivated behaviors and emotional conditioning, whereas instrumental appetitive or discriminatory conditioning is essentially spared. A similar behavioral profile was reported in a rat schizophrenia model with impaired active avoidance, latent inhibition, and water maze reversal learning as well as decreased exploration but spared performance in appetitively motivated nonmatch-toposition conditioning (Flagstad et al., 2005). Decreased response suppression during CER trials might specifically relate to the psychotic symptoms and emotional changes reported in some $\alpha$-mannosidosis patients (Gutschalk et al., 2004; Seidl et al., 2005). Older work in rats has shown that psychotomimetic drugs indeed attenuate response suppression in a CER schedule (Davis, 1990), whereas increased response suppression is part of the antipsychotic profile of some neuropharmacological agents (Stanhope et al., 2001).

Decreased anxiety and response suppression may seem to contrast with the decreased exploratory behavior also observed in the knock-outs. However, it is well established that exploratory and conflict tests are behaviorally and pharmacologically distinct from conditioned fear tests (Davis, 1990), although the neurobiological basis of the difference remains poorly understood. Again, damage to hippocampus and related cortical regions may have contributed to the deficits observed here in $\alpha$-mannosidasedeficient mice. Open field exploration is often decreased after hippocampal and neocortical damage (Moses et al., 2002; Wright et al., 2004), and Moses et al. (2002) ascribed the decreased exploratory activity in hippocampus-lesioned rats to specific spatial memory deficits. Several studies have demonstrated that CER acquisition definitely involves a functional network that includes hippocampus and prefrontal cortex (Lane et al., 1982; Zielinski et al., 1993; Barrett et al., 2003). Disruptive electric stimulation of hippocampus inhibits CER acquisition (Shinkman and Kaufman, 1972), and acquisition of tone-shock associations induces an increase in hippocampal metabolic activity (Barrett et al., 2003).

The generation of a mouse model that displays many of the typical biochemical, neuropathological, and behavioral characteristics of human $\alpha$-mannosidosis will be an important tool in future studies on the pathophysiology of this disorder and the evaluation and development of safe and effective therapeutic strategies. Techniques based on bone marrow transplantation appear to work well in some animal models but not in others, as well as in some patients, but safety and feasibility as a general treatment remain debatable (Sun and Wolfe, 2001; Thomas, 2001; Grewal et al., 2004). Roces et al. (2004) recently reported the first results that show high efficacy of enzyme replacement therapy in $\alpha$-mannosidase-deficient mice, but evaluation of long-term effects and functional benefits is still required.

\section{References}

Ara JR, Mayayo E, Marzo ME, Guelbenzu S, Chabas A, Pina MA, Calderon C (1999) Neurological impairment in $\alpha$-mannosidosis: a longitudinal clinical and MRI study of a brother and sister. Childs Nerv Syst 15:369-371.

Aronson NNJ, Kuranda MJ (1989) Lysosomal degradation of Asn-linked glycoproteins. FASEB J 3:2615-2622

Autio S, Louhimo T, Helenius M (1982) The clinical course of mannosidosis. Ann Clin Res 14:93-97.

Balschun D, Manahan-Vaughan D, Wagner T, Behnisch T, Reymann KG, Wetzel W (1999) A specific role for group I mGluRs in hippocampal LTP and hippocampus-dependent spatial learning. Learn Mem 6:138-152.

Barrett D, Shumake J, Jones D, Gonzalez-Lima F (2003) Metabolic mapping of mouse brain activity after extinction of a conditioned emotional response. J Neurosci 23:5740-5749.

Bennet JK, Dembure PP, Elsas LJ (1995) Clinical and biochemical analysis of two families with type I and type II mannosidosis. Am J Med Genet 55:21-26.

Berg T, Hopwood JJ (2002) $\alpha$-Mannosidosis in the guinea pig: cloning of the lysosomal $\alpha$-mannosidase cDNA and identification of a missense mutation causing $\alpha$-mannosidosis. Biochim Biophys Acta 1586:169-176.

Brandeis R, Brandys Y, Yehuda S (1989) The use of the Morris water maze in the study of memory and learning. Int J Neurosci 48:29-69.

Bunsey M, Eichenbaum H (1996) Conservation of hippocampal memory function in rats and humans. Nature 379:255-257.

Burditt LJ, Chotai K, Hirani S, Nugent PG, Winchester BG, Blakemore WF (1980) Biochemical studies on a case of feline mannosidosis. Biochem J 189:467-474

Chishti MA, Yang DS, Janus C, Phinney AL, Horne P, Pearson J, Strome R, Zuker N, Loukides J, French J, Turner S, Lozza G, Grilli M, Kunicki S, Morissette C, Paquette J, Gervais F, Bergeron C, Fraser PE, Carlson GA, et al. (2001) Early-onset amyloid deposition and cognitive deficits in transgenic mice expressing a double mutant form of amyloid precursor protein 695. J Biol Chem 276:21562-21570.

Coenen R, Gieselmann V, Lüllmann-Rauch R (2001) Morphological alter- 
ations in the inner ear of the arylsyulfatase-deficient mouse. Acta Neuropathol (Berl) 101:491-498.

Crawley AC, Jones MZ, Bonning LE, Finnie JW, Hopwood JJ (1999) $\alpha$-Mannosidosis in the guinea pig: a new animal model for lysosomal storage disorders. Pediatr Res 46:501-509.

Crawley JN (1999) Behavioral phenotyping of transgenic and knockout mice: experimental design and evaluation of general health, sensory functions, motor abilities, and specific behavioral tests. Brain Res 835:18-26.

Cummings JF, Wood PA, de Lahunta A, Walkley SU, Le Boeuf L (1988) The clinical and pathologic heterogeneity of feline alpha-mannosidosis. J Vet Intern Med 2:163-170.

Davis M (1990) Animal models of anxiety based on classical conditioning: the conditioned emotional response (CER) and the fear-potentiated startle effect. Pharmacol Ther 47:147-165.

Desnik RJ, Sharp HL, Grabowski GA, Brunning RD, Quie PG, Sung JH, Gorlin RJ, Ikonne JU (1976) Mannosidosis: clinical, morphologic, immunologic, and biochemical studies. Pediatr Res 10:985-996.

D'Hooge R, De Deyn PP (2001) Applications of the Morris water maze in the study of learning and memory. Brain Res Rev 36:60-90.

Enthoven L, Dalm S, de Kloet ER, Oitzl MS (2004) Swim posture of mice does not affect performance in the water maze. Brain Res 1003:36-41.

Flagstad P, Glenthøj BY, Didriksen M (2005) Cognitive deficits caused by late gestational disruption of neurogenesis in rats: a preclinical model of schizophrenia. Neuropsychopharmacology 30:250-260.

Florian C, Roullet P (2004) Hippocampal CA3-region is crucial for acquisition and memory consolidation in Morris water maze task in mice. Behav Brain Res 154:365-374.

Frick KM, Burlingame LA, Arters JA, Berger-Sweeney J (2000) Reference memory, anxiety and estrous cyclicity in C57BL/6NIA mice are affected by age and sex. Neuroscience 95:293-307.

Gallagher M, Holland PC (1992) Preserved configural learning and spatial learning impairment in rats with hippocampal damage. Hippocampus 2:81-88.

Gerlai R, Henderson JT, Roder JC, Jia Z (1998) Multiple behavioral anomalies in GluR2 mutant mice exhibiting enhanced LTP. Behav Brain Res 95:37-45.

Grewal SS, Shapiro EG, Krivit W, Charnas L, Lockman LA, Delaney KA, Davies SM, Wenger DA, Rimell FL, Abel S, Grovas AC, Orchard PJ, Wagner JE, Peters C (2004) Effective treatment of $\alpha$-mannosidosis by allogeneic hematopoietic stem cell transplantation. J Pediatr 144:569-573.

Gutschalk A, Harting I, Cantz M, Springer C, Rohrschneider K, Meinck HM (2004) Adult alpha-mannosidosis: clinical progression in the absence of demyelination. Neurology 63:1744-1746.

Hocking JD, Jolly RD, Batt RD (1972) Deficiency of $\alpha$-mannosidase in Angus cattle: an inherited lysosomal storage disease. Biochem J 128:69-78.

Jolas T, Zhang XS, Zhang Q, Wong G, Del Vecchio R, Gold L, Priestley T (2002) Long-term potentiation is increased in the CA1 area of the hippocampus of APP(swe/ind) CRND8 mice. Neurobiol Dis 11:394-409.

Jolly RD, Thompson KG (1978) The pathology of bovine mannosidosis. Vet Pathol 15:141-152.

Lane JD, Sands MP, Co C, Cherek DR, Smith JE (1982) Biogenic monoamine turnover in discrete rat brain regions is correlated with conditioned emotional response and its conditioning history. Brain Res 240:95-108.

Morris RG, Garrud P, Rawlins JN, O'Keefe J (1982) Place navigation impaired in rats with hippocampal lesions. Nature 297:681-683.

Moses SN, Sutherland RJ, McDonald RJ (2002) Differential involvement of amygdala and hippocampus in responding to novel objects and contexts. Brain Res Bull 58:517-527.

Muntz FH, Bonning LE, Carey WF (1999) Alpha-mannosidosis in a guinea pig. Lab Anim Sci 49:424-426.

Noll RB, Kulkarni R, Netzloff ML (1986) Follow-up of language and cognitive development in patients with mannosidosis. Arch Neurol 43:157-159.

Noll RB, Netzloff ML, Kulkarni R (1989) Long-term follow-up of biochemical and cognitive functioning in patients with mannosidosis. Arch Neurol 46:507-509.
Owayed A, Clarke JTR (1997) Hyperphagia in patients with $\alpha$-mannosidosis type II. J Inherit Metab Dis 20:727-728.

Roces DP, Lüllmann-Rauch R, Peng J, Balducci C, Andersson C, Tollersrud O, Fogh J, Orlacchio A, Beccari T, Saftig P, von Figura K (2004) Efficacy of enzyme replacement therapy in $\alpha$-mannosidosis mice: a preclinical animal study. Hum Mol Genet 13:1979-1988.

Seidl U, Giesel FL, Cantz M, Schmidbauer M, Schroder J, Pantel J (2005) Unusual course of alpha-mannosidosis of paranoid-hallucinatory psychosis. Nervenarzt 76:335-338.

Shapiro EG, Lockman LA, Balthazor M, Krivit W (1995) Neuropsychological outcomes of several storage diseases with and without bone marrow transplantation. J Inherit Metab Dis 18:413-429.

Shinkman PG, Kaufman KP (1972) Posttrial hippocampal stimulation and CER acquisition in the rat. J Comp Physiol Psychol 80:283-292.

Skinner DM, Martin GM, Harley C, Kolb B, Pridgar A, Bechara A, van der Kooy D (1994) Acquisition of conditional discriminations in hippocampal lesioned and decorticated rats: evidence for learning that is separate from both simple classical conditioning and configural learning. Behav Neurosci 108:911-926.

Stanhope KJ, Mirza NR, Bickerdike MJ, Bright JL, Harrington NR, Hesselink MB, Kennett GA, Lightowler S, Sheardown MJ, Syed R, Upton RL, Wadsworth G, Weiss SM, Wyatt A (2001) The muscarinic receptor agonist xanomeline has an antipsychotic-like profile in the rat. J Pharmacol Exp Ther 299:782-792.

Stewart CA, Morris RGM (1993) The watermaze. In: Behavioral neuroscience. A practical approach (Sahgal A, ed), pp 107-122. Oxford: IRL.

Stinchi S, Lüllmann-Rauch R, Hartmann D, Coenen R, Beccari T, Orlacchio A, von Figura K, Saftig P (1999) Targeted disruption of the lysosomal $\alpha$-mannosidosase gene results in mice resembling a mild form of human $\alpha$-mannosidosis. Hum Mol Genet 8:1365-1372.

Sun H, Wolfe JH (2001) Recent progress in lysosomal $\alpha$-mannosidase and its deficiency. Exp Mol Med 33:1-7.

Sung JH, Hayano M, Desnick RJ (1977) Mannosidosis: pathology of the nervous system. J Neuropathol Exp Neurol 36:807-820.

Suzuki K, Vanier MT, Suzuki K (1999) Lysosomal disorders. In: Mouse models in the study of genetic neurological disorders (Popko B, ed), pp 245-283. New York: Kluwer Academic.

Tardy C, Andrieu-Abadie N, Salvayre R, Levade T (2004) Lysosomal storage diseases: is impaired apoptosis a pathogenic mechanism? Neurochem Res 29:871-880.

Taverna FA, Georgiou J, McDonald RJ, Hong NS, Kraev A, Salter MW, Takeshima H, Muller RU, Roder JC (2005) Defective place cell activity in nociceptin receptor knockout mice with elevated NMDA receptordependent long-term potentiation. J Physiol (Lond) 565:579-591.

Thomas GH (2001) Disorders of glycoprotein degradation: $\alpha$-mannosidosis, $\beta$-mannosidosis, fucosidosis, and sialidosis. In: The metabolic and molecular bases of inherited diseases, Ed 8 (Scriver CR, Beaudet AL, Valle D, Sly WS, Childs B, Kinzler KW, Vogelstein B, eds), pp 3507-3533. New York: McGraw-Hill.

Walkley SU, Baker HJ, Rattazzi MC, Haskins ME, Wu JY (1991) Neuroaxonal dystrophy in neuronal storage disorders: evidence for major GABAergic neuron involvement. J Neurol Sci 104:1-8.

Walkley SU, Thrall MA, Dobrenis K, Huang M, March PA, Siegel DA, Wurzelmann S (1994) Bone marrow transplantation corrects the enzyme defect in neurons of the central nervous system in a lysosomal storage disease. Proc Natl Acad Sci USA 91:2970-2974.

Wright JW, Murphy ES, Elijah IE, Holtfreter KL, Davis CJ, Olson ML, Muhunthan K, Harding JW (2004) Influence of hippocampectomy on habituation, exploratory behavior, and spatial memory in rats. Brain Res 1023:1-14.

Zielinski K, Walasek G, Werka T, Wesierska M, Gradkowska M, OderfeldNowak B (1993) Effects of partial lesion of dorsal hippocampal afferent and GM1 ganglioside treatment on conditioned emotional response and hippocampal afferent markers in rats. Behav Brain Res 55:77-84. 